NBER WORKING PAPER SERIES

LIFE CYCLE ANNUITY VALUATION

B. Douglas Bernheim

Working Paper No. 1511

NATIONAL BUREAU OF ECONOMIC RESEARCH

1050 Massachusetts Avenue

Cambridge, MA 02138

December 1984

Financial support from the Center for Economic Policy Research is gratefully acknowledged. I am indebted to Kyle Bagwell for able research assistance, and to Debbie Olson and Lucia Alviano for technical preparation of this manuscript. I would also like to thank Michael Boskin, Michael Hurd, Joel Slemrod and Lawrence Summers for helpful comments and discussions. The research reported here is part of the NBER's research programs in Taxation and Pensions and project in Government Budget. Any opinions expressed are those of the author and not those of the National Bureau of Economic Research. 


\title{
Life Cycle Annuity Valuation
}

\begin{abstract}
In this paper, we argue that actuarial valuation of annuity benefit streams is theoretically inconsistent with the assumption of pure life cycle motives. Instead, we show that the simple discounted value of future benefits (ignoring the possibility of death) is often a good approximation to the relevant concept of value. This observation motivates a re-examination of existing empirical evidence concerning the effects of Social Security on personal savings, retirement, and the distribution of wealth, as well as the proper computation of age-wealth profiles. The conceptual points raised here are also relevant for eva1uating the relative merits of wage and consumption taxes. In each case, we argue that the use of simple, rather than actuarial discounting of survival-contingent income streams dramatically alters the conclusions of previous studies.
\end{abstract}

B. Douglas Bernheim Department of Economics Stanford University 404 Encina Hall Stanford, CA. 94305 


\section{Introduction}

Most empirical analyses of the behavioral and distribution consequences of public retirement annuity provision (e.g. Social Security) are based upon simple life cycle models where, in particular, individuals have no bequest motives, and lifespans are certain. In moving from tractable theoretical models to empirical implementation, such studies typically accomodate uncertain lifespans by employing actuarial discounting to compute the 'values' of annuity benefit streams (see, for example, Feldstein's [1974] analysis of personal savings). In this paper, we argue that the practice of employing actuarial valuation cannot be reconciled with models encompassing pure life cycle motives, and that this practice systematically biases results in predictable directions. Instead, we show that under very general conditions (discussed below), the simple discounted value of benefits (ignoring the possibility of death) is ordinarily a good approximation to the relevant concept of value.

The intuition for these results is straightforward. Actuarial valuation is appropriate only if annuity markets are perfect, in which case positive holdings of bequeathable assets are inconsistent with pure life cycle motives (see Yaari [1965]). To rescue the life cycle hypothesis, it is necessary to assume a partial or complete failure of annuity markets. In particular, one can explain the presence of bequeathable wealth in either of two ways.

First, one might assume that groups of individuals (typically friends or family, who share private information concerning survival probabilities) contrive imperfect substitutes for annuity markets by 
pooling risks. The 'value' of an annuity will then exceed its actuarial value by a risk premium, but the magnitude of this premium will be related to the size of the group (in the limit, as the group becomes infinitely large, the premium shrinks to zero). Kotlikoff and Spivak [1981] have shown that even relatively small groups manage to appropriate a large fraction of the potential surplus available from risk sharing.

It may, however, be difficult to enforce non-contractual agreements between family members, other than spouses. I/ Furthermore, there is reason to believe that the advantages of risk pooling between spouses may be overstated. $2 /$ In the absence of compelling empirical evidence establishing the prevalence of such arrangements, it is therefore important to consider the case in which imperfect substitutes for annuity markets are unavailable; indeed, most theoretical and empirical work in this area proceeds on this basis.

When 'homemade' risk pooling arrangements are unavailable, positive holdings of bequeathable wealth can be reconciled with life cycle motives only if annuity markets fail completely (Yaari [1965]), or if insurance market equilibrium involves quantity constraints, so that annuities are unavailable on the margin. Under these circumstances, the value of an annuity is suggested by the following hypothetical exercise: how much bequeathable wealth would one have to give a life cycle saver to compensate him for the loss of an annuity which pays $\$ 1$ per year? A bequeathable asset which pays $\$ 1$ per year costs $\$ 1 / r$ (where $r$ is the rate of interest). Of course, it generates income even if the individ- 
ual dies, while the annuity does not. However, this difference is irrelevant to the pure life cycle saver: both assets generate the same survival-contingent income stream, and the absence of annuity markets precludes the consumer from selling the death-contingent stream associated with his bequeathable asset. So far as he is concerned, the only relevant difference between these two assets is that he cannot consume the principal of the annuity (he cannot sell the rights to future benefits). But if the date at which he plans to drive his bequeathable wealth to zero is sufficiently distant, the benefits associated with being able to consume the principal of the marginal asset are negligible. In such cases, simple discounting of annuity benefits (computed as if the consumer will live forever) is therefore a good approximation to value.

This paper is organized as follows. In Section 2, we formalize the preceeding argument within the context of a simple life cycle model with an uncertain horizon. Annuity values are calculated for a range of hypothetical parameter values. In Section 3, we discuss the implications of employing simple, rather than actuarial, valuation for several empirical problem areas, including the effects of Social Security on personal savings, retirement, and the distribution of wealth, as well as the proper computation of age-wealth profiles. Our central results also form the basis for some remarks concerning the comparison of wage and consumption taxes. In each case, we argue that the use of simple, rather than actuarial valuation of survival-contingent income streams dramatically alters the conclusions of previous studies. The paper closes with a brief conclusion. 
2. Annuity Valuation

When annuity markets fail and consumers are risk averse, the true value of an annuity exceeds its actuarial value by a risk premium. In this section, we calculate the magnitude of this premium within the context of a simple life cycle model.

We will assume that lifetime utility is intertemporally separable and homothetic, and that each consumer has a constant pure rate of time preference $\rho$, and a constant instantaneous survival probability $1-\pi \cdot \underline{3} /$ Under these assumptions, the only utility functions consistent with Yaari's [1965] formulation of the consumer's optimal control program have the form

$$
\frac{1}{\alpha} \int_{0}^{\infty} e^{-\lambda t} C_{t}^{\alpha} d t
$$

where $\lambda=\rho+\pi$. At time 0 , the individual is endowed with some level of bequeathable wealth, $w_{0}$, which earns a rate of return $r . \underline{4}$ Beginning in period I (representing retirement), he receives income from an exogenous annuity. Anuity benefits $A_{t}$ thereafter grow at the rate $g$; thus,

$$
A_{t}=\left\{\begin{array}{cc}
0 & t<L \\
e^{g(t-L)} A_{L} & t \geqq L
\end{array}\right.
$$

The choice of a particular consumption profile determines the evolution of bequeathable wealth, as follows:

$$
\dot{\mathrm{W}}_{t}=r \mathrm{~W}_{t}+\mathrm{A}_{t}-\mathrm{C}_{\mathrm{t}}
$$


The consumer is constrained in two ways. First, his resources must be sufficient to finance planned consumption in all states of nature; thus,

$$
\int_{0}^{\infty}\left(C_{t}-A_{t}\right) e^{-r t} d t \leqq w_{0}
$$

Further, the absence of annuity markets implies that he is unable to finance current consumption by selling (borrowing on) future annuity benefits, $\underline{5 /}$ so

$$
W_{t}=e^{r t} W_{0}-\int_{0}^{t}\left(C_{\tau}-A_{\tau}\right) e^{r(t-\tau)} d \tau \geqq 0 .
$$

By considering perturbations of the planned consumption profile, we see that as long as bequeathable wealth is positive at $t$ and $\tau$, the optimal program must satisfy

$$
C_{t}=e^{\gamma(t-\tau)} C_{\tau}
$$

where $\gamma \equiv(r-\lambda) /(1-\alpha)<r . \underline{6}$ Ignoring the non-negativity constraints (4), it is easy to see that the optimal program is given by

$$
c_{t}=(r-r)\left(w_{t}+v_{t}\right)
$$

where wealth evolves according to

$$
\left(w_{t}+v_{t}\right)=\left(w_{0}+v_{0}\right) e^{\gamma t}
$$

and where we define 


$$
V_{t}= \begin{cases}\frac{A_{t}}{r-g} & t \geqq L \\ V_{L} e^{r(t-L)} & t<L\end{cases}
$$

Of course, there is no guarantee that the program described by (6), (7), and (8) is feasible, given (4). To proceed, it is necessary to classify the various ways in which (4) may bind. First, it is clear from (2) and (8) that if $\gamma>g$, there exists some $\tau$ such that if $t>\tau, W_{t}$ (as given in equation $(7)$ ) would necessarily exceed 0 $\left(w_{t}+v_{t}\right.$ grows at the rate $\gamma$, while $v_{t}$, after $L$, grows at the rate g). Conversely, if $\gamma<g$, $W_{t}$ (as given by (7)) would at some point necessarily fall below, and remain below 0 . We refer to these as case I $(\gamma \geqq g)$ and case II $(\gamma<g)$.

We divide these two cases into subcategories, according to whether, along the optimal plan, $\mathrm{w}_{\mathrm{t}} \geqq 0$ binds (cases $\mathrm{Ib}$ and IIb) or does not bind (cases Ia and IIa) at $\mathrm{L}$ (given the form of the utility function, it will never bind before $\mathrm{L}$, since at $C_{t}=0$ the individual has infinite marginal utility of consumption). These four cases are exhaustive. We consider each in turn.

Case Ia: $\gamma \geqq g, W_{L}>0$. In this case, the program described in (6), (7), and (8) never violates (4), so it is optimal. The evolution of $C, A$, and $W$ is depicted in panel Ia of Figure 1 (note: $A_{L}$ need not exceed $\left.C_{L}\right)$. Observe that the annuity wealth term, $A_{t} /(r-g)$, is equal to the simple discounted value of future benefits (ignoring death). Swapping a bequeathable asset worth $\$ 1$ for an annuity which pays $\$$ r per 
year until death will not alter the optimal program, or affect utility. Intuitively, unless an individual plans to consume his principal at some point in the future, he will be indifferent between these two assets (both generate the same survival contingent income stream). An interesting feature of this regime is that the value of insurance is independent of the consumer's risk aversion parameter, $\alpha$. Whether or not we are in this regime is, as well, often independent of $\alpha \cdot \underline{71}$

Case Ib: $\quad \gamma \geqq g, W_{L}=0$. The consumer completely exhausts $W_{O}$ over $[0, \mathrm{~L}]$, with $\mathrm{C}_{\mathrm{t}}$ obeying (5). At $\mathrm{L}$, consumption rises discontinuously, but $C_{L}<A_{I}$, so that bequeathable assets begin to accumulate once again. Thereafter, $C_{t}$ obeys (5). This pattern is depicted in panel Ib of Figure I.

Shifting resources from bequeathable wealth to annuities necessarily alters the optimal program, depressing consumption prior to L and raising it thereafter. In this case, simple discounting is only approximately appropriate, and the accuracy of the approximation depends upon the magnitude of the discontinuity at $L$. In particular,

$$
\left.\frac{d W_{0}}{d V_{0}}\right|_{U^{*}}=-\left[\left.\frac{\mathrm{C}_{\mathrm{L}-}}{\mathrm{C}_{\mathrm{L}+}}\right|^{1-\alpha}\right.
$$

( $\mathrm{C}_{\mathrm{L}-}$ and $\mathrm{C}_{\mathrm{L}+}$ are defined, respectively, as the left and right hand limits of $C_{t}$ as $t$ approaches $\left.L\right)$. Thus, when $C_{L-}=C_{L_{+}}$, simple discounting is exactly appropriate. 
Within this regime, higher risk aversion may either increase or decrease the marginal value of insurance. One effect is obvious: since $\mathrm{C}_{\mathrm{L}-}<\mathrm{C}_{\mathrm{L}^{+}}$, the consumer is "overinsured," and more risk averse individuals will have a stronger desire to smooth the discontinuity (further annuitization accentuates the discontinuity). However, there is a second effect: the degree of risk aversion affects the magnitude of $\mathrm{C}_{\mathrm{L}-} / \mathrm{C}_{\mathrm{L}+} \cdot$ Higher risk aversion rotates the consumption profiles both before and after $L$ to flatter positions. If $\gamma>0$, this increases the discontinuity--since this works in the same direction as the previous effect, risk averse individuals will place a lower value on insurance. If $\gamma<0$, this rotation works in the opposite direction, and the net effect of risk aversion on annuity valuation is ambiguous.

Case IIa: $\gamma<\mathrm{g}, \mathrm{W}_{\mathrm{L}}>0$. This is the most interesting case, since it applies to an individual who reaches retirement with positive resources, whose real annuity profile is relatively flat $(g \approx 0)$, and who dissaves after retirment $(\gamma<0)$. There is strong empirical evidence indicating that these features characterize most consumers (see Bernheim [1984a], King and Dicks-Mireaux [1982], or Diamond and Hausman [1980]). It is also the most difficult case, and so warrants careful attention.

The qualitative pattern is depicted in panel IIa of Figure 1. Along the optimal program, consumption will obey the first order condition (5) as long as wealth is positive; however, once (4) binds, we will simply have $C_{t}=A_{t}$. Let $T$ denote the age at which (4) first binds. Then the first order conditions imply that 


$$
c_{t}= \begin{cases}e^{\gamma t} C_{0} & t<T \\ A_{t} & t \geqq T\end{cases}
$$

From the resource constraint, we have

$$
w_{0}=\int_{0}^{T}\left(C_{t}-A_{t}\right) e^{-r t} d t .
$$

Finally, it is easy to see that despite the binding constraint, consumption must be continuous in time, so that

$$
e^{\gamma^{T}} C_{O}=e^{g(T-L)} A_{L}
$$

Unfortunately, the solution is highly non-linear, so the appropriate "value" of an annuity cannot be inferred directly from an equation such as (7). Instead, we calculate the compensating variation associated with annuitization. This is done by changing $A_{L}$ (with associated changes in $\left.A_{t}\right)$, and allowing wealth to adjust endogenously so that utility is held constant:

$$
\frac{1}{\alpha} \int_{0}^{\infty} e^{-\lambda t} C_{t}^{\alpha} d t=U^{*}
$$

where $U^{*}$ is fixed at the level associated with the initial program. Given $U^{*}$ and $A_{L}$, equations (2), (9), (10), (11) and (12) determine $W_{0}, C_{0}$, and $T$ (we use (2) and (9) to substitute out for $A_{t}$ and $C_{t}$, leaving 3 equations in 3 unknowns).

This system of equations can be differentiated implicitly to yield, after some tedious manipulations, $8 /$ 


$$
\left.\frac{d C_{0}}{d V_{0}}\right|_{U^{*}}=-\phi(r-\gamma) \frac{e^{(g-r)(T-L)}}{1-e^{(\gamma-r) T}}
$$

and

$$
\left.\frac{d W_{0}}{d V_{0}}\right|_{U^{*}}=-1+(1-\phi) e^{(g-r)(T-L)} \equiv-1+\xi
$$

where

$$
\phi=\frac{r-g}{\lambda-\alpha g}
$$

Since $\gamma<g<r$, it is easy to show that $\lambda-\alpha g>r-g>0$, from which we can immediately conclude that

$$
\left.\frac{\mathrm{dc}_{0}}{\mathrm{dV_{0 }}}\right|_{\mathrm{U}^{*}}<0
$$

and

$$
-1<\left.\frac{\mathrm{dW}_{0}}{\mathrm{dV_{0 }}}\right|_{\mathrm{U}^{*}}<0
$$

Intuitively, since (4) may bind at some point, the annuity is worth less than an asset which yields the same yearly income. As $T$ goes to infinity (or $\gamma$ to $g$ ), this event becomes more remote, so naturally the value of annuitization approaches $A_{0} /(r-g)$.

Equations (14) and (15) tell us that when $\gamma<g$, the marginal value of an annuity is equal to the simple discounted value of future benefits (calculated as if the individual will live forever), minus a proportional adjustment factor. How large is the adjustment? It is impossible to say without substituting numerical values. 
The results of calculations based on alternative hypothetical parameter values are presented in Table 1 . We consider real interest rates $(r)$ of $1 \%, 3 \%$ and $5 \%$, felicity discount rates $(\lambda)$ of $5 \%$ and $7 \%$, and relative risk aversion coefficients $(\alpha)$ of $0,-1$, and -2 . All eighteen permutations of these values are included; throughout, we set the growth rate of annuity benefits (g) equal to zero (more on this below), the length of an individual's preretirement economic life (L) equal to 40 , and the ratio of annuity wealth to bequeathable wealth at retirement $\left(V_{L} / W_{L}\right)$ equal to 2. This last value is roughly consistent with empirical evidence on retirees (see Bernheim [1984a]); if anything, the large assumed relative magnitude of annuity wealth will tend to generate small values of $T$, thereby overstating the difference between simple discounted value and compensating variation.

For each set of parameter values, we report $\gamma, T-L$, the ratio of the compensating variation associated with the marginal annuity to its simple discounted value $(\mathrm{MV} / \mathrm{SDV}=1-\xi)$, and the approximate ratio of the value of all annuities held by this consumer to their simple discounted value (AV/SDV). The last of these calculations is based on numerical integration--the true relationship is highly non-linear, and analytic integration is impossible.

Calculated values of $\gamma$ lie between -.06 and 0 . Evidence on dissaving among retirees leads us to believe that $\gamma$ typically lies between -.04 and 0 (see Bernheim [1984a])--the plausibility of particular parametric values should be judged accordingly. Note that even when rates of dissaving are relatively high, the associated unconstrained interval ( $T$ ) is quite long. 
For $r=0.03$ and 0.05 , simple discounting approximates annuity values extremely well. Only for very low risk aversion $(\alpha=0)$ and high felicity discounting $(\lambda=.07)$ does the value of the marginal annuity fall below $80 \%$ of its simple discounted value, and the value of all annuities below $90 \%$. In contrast, actuarial discounting is much less accurate. Assuming a single year survival probability of .95 (this is approximately appropriate for an individual of retirement age), actuarial values at retirement are only $37.5 \%$, and $50 \%$ of simple discounted values (depending on whether $r=0.03$ or 0.05 ). In all cases, simple discounting is far superior.

For $r=0.01$, simple dicounting performs less well. However, this conclusion should be tempered by two comments. First, in this case, actuarial values at retirement are only $16.7 \%$ of simple discounted values, which implies that, even in the most favorable case, actuarial discounting understates total annuity valuation by a factor of almost three. Second, the 'poor' performance of simple discounting is directly attributable to the difference between $r$ and $g$ (this can be seen from equation (14): since $g-r=-.01$, the adjustment factor is discounted very little even though $\mathrm{T}$ is large). If one believes that inflation erodes private pension values so that $g$ is, say, -0.02 , then once again the accuracy of simple discounting will be evident. Equations (14) and (15) also allow us to draw some qualitative conclusions concerning the role of risk aversion in determining the value of insurance provided by annuities. If $g=0$ (annuities pay a constant real streat), the coefficient of relative risk aversion $(\alpha)$ 
appears only through its effect on T. As a falls (the individual becomes more risk averse), $|\gamma|$ falls. Since this flattens the consumption profile, T rises. From (9), the marginal value of an annuity rises as well, as we would expect. As a $\alpha$ goes to $-\infty, T$ approaches infinity, and the value of an annuity rises to $\mathrm{A} / \mathrm{r}$ (intuitively, it is less likely that the constraint well ever bind). As $\alpha$ approaches 1 (risk neutrality), $\gamma$ goes to $\infty$ and $T$ to 0 --before we reach this limit, we move into regime IIb. However, if $\mathrm{L}=0$ so that we remain in IIa, the limiting value of the annuity is $\mathrm{A} / \lambda$ (intuitively, future consumption is discounted at the rate $\lambda>r$ ). Note that this is the actuarial value of the benefit stream only if we discount by the individual's pure rate of time preference, rather than by the market rate of interest. In a strict sense, not even risk neutrality justifies actuarial valuation, as typically defined! $9 /$

Case IIb: $\gamma<\mathrm{g}, \mathrm{W}_{\mathrm{L}}=0$. As in Ib, the consumer completely exhausts $W_{0}$ over $[0, L]$, with $C_{t}$ obeying (5). At $L$, consumption rises discontinuously, but since the desired consumption profile falls more rapidly than his annuity profile, he is immediately constrained to consume exactly his annuity benefit. This pattern is depicted in panel IIb of Figure 1.

As before, additional annuitization raises consumption after $\mathrm{L}$, and depresses it before. However, in this case, $10 /$

$$
\left.\frac{\mathrm{dC}_{0}}{\mathrm{dV}_{0}}\right|_{\mathrm{U}^{*}}=-\phi\left|\frac{\mathrm{C}_{\mathrm{L}-}}{\mathrm{C}_{\mathrm{L}+}}\right|^{1-\alpha}
$$


Again we see that simple discounting approximates true value, but in this case there are two adjustment factors. First, as in Ib, additional annuitization magnifies the discontinuity at L. Second, as in IIa, additional annuitization forces the individual to choose a consumption profile with the wrong slope (this is captured by $\phi$ ).

The effect of risk aversion on annuity valuation is ambiguous here, and the analysis parallels that for regime Ib. We leave the details to the readers.

The model considered here is, of course, quite restrictive. We have employed specific functional forms (e.g. survival probabilities are constant; utility is intertemporally separable and has constant elasticity), and have ignored the problems which arise when the relevant decision unit is a family or household. While these considerations undoubtably effect our hypothetical calculations, we believe that our basic qualitative results are quite robust. In particular, regardless of functional forms, if the individual has no desire to borrow on future annuity benefits, simple discounting is exactly correct; if this desire arises only in the distant future (when bequeathable wealth reaches zero), simple discounting yields a good approximation to value. By the same reasoning, for households consisting of more than one member, simple discounting will be (approximately) appropriate for the assumable portion of annuity benefits. A large fraction of Social Security benefits are assumable by a surviving spouse, and many private pensions are fully assumable. 


\section{Implications}

In this section, we apply the preceding analysis to several important empirical questions concerning behavior and distribution. It is, of course, far from clear that one ought to use compensating variation as a measure of value in a behavioral context, so it is necessary to supplement the analysis of Section 2. In each case, we find that the use of simple discounting would dramatically alter the conclusions of earlier authors, who employed actuarial valuation. Our central results also form the basis of some remarks concerning consumption and wage taxation.

\section{A. Personal Saving and Asset Substitution}

The question of whether (and to what extent) Social Security displaces personal wealth accumulation is, by now, a familiar one. In his seminal work, Feldstein [1974] employed a simple life cycle model with certain lifespans to show that, abstracting from the effects of induced retirement, Social Security would displace private savings "dollar for dollar". In moving to his empirical implementation, Feldstein used actuarial values to accomodate uncertain horizons. While more recent studies have modified his estimation procedure in a variety of ways (producing a range of estimates), the practice of employing actuarial values has been nearly universal. 1 l/ Yet, as we have argued, actuarial valuation is inconsistent with life cycle assumptions. $12 /$ One might defend this practice by arguing that the life cycle model outlined by Feldstein is merely suggestive--the notion that Social Security displaces personal savings is, perhaps, not intrinsically tied 
to this particular formulation of consumer behavior. Specifically, if we assume that consumers have bequest motives, it is entirely consistent to posit efficient annuity markets, in which case actuarial valuation is appropriate.

Unfortunately, this argument runs afoul of a severe conceptual difficulty. In the world outlined above each consumer will have an optimal degree of annuitization. When the government imposes compulsory saving for retirement annuities, consumers will alter their investment strategies to offset not only the additional savings, but also the additional annuitization. That is, in such a world, Social Security should displace private pensions dollar for dollar, leaving bequeathable wealth unaffected. Yet microeconomic estimates of this relationship (such as Feldstein and Pellechio [1979], Kotlikoff [1979] and King and DicksMireaux [1983]) employ bequeathable wealth as the dependent variable. By finding that the coefficient of Social Security is significantiy different from zero, these studies effectively reject the hypotheses upon which the use of actuarial valuation is based!

In general, unless insurance markets fail completely, Social Security will, at least in some regimes, alter insurance holdings rather than bequeathable wealth. When discretionary annuity holdings are positive, Social Security simply displaces annuities; when term life insurance is positive, consumers neutralize increases in Social Security by purchasing additional insurance (in both cases, these conclusions apply to a Social Security system which is "fair" using survival probabilities implicit in market prices of insurance; "unfair" Social 
Security would, in addition, generate an income effect). Unless estimation procedures make use of information identifying appropriate regimes (i.e., whether annuities or term life insurance holdings are positive), the use of bequeathable wealth as a dependent variable may involve severe econometric mispecification. In Bernheim [1984b], we elaborate on these issues, and discuss consistent estimation of assetannuity substitution in the presence of imperfect insurance markets. When insurance market failure is severe or complete, the investigator can safely confine his attention to the relationship between compulsory annuities and bequeathable assets. In the presence of nontrivial bequest motives, appropriate valuation of Social Security wealth is problematic, and there is, of course, no reason to believe that the rate of displacement should be dollar-for-dollar. On the other hand, for pure life cycle assumptions, the analysis of Section 2 creates a presumption in favor of simple discounting.

Is the simple discounted value of benefit streams the appropriate variable for behavioral relationships concerning life cycle savings? To answer this question, we must return to the theoretical model of Section 2. We will confine attention to the two cases in which $\mathrm{W}_{\mathrm{L}}>0$ (Ia and IIa).

Consider first case Ia. Suppose we consider a change in $V_{t}$ (increasing the level of benefits while preserving $g$ and $L$ ) for which total initial resources,

$$
\mathrm{R}_{0} \equiv \mathrm{w}_{0}+\mathrm{v}_{0},
$$


are held constant. What effect will this have on $W_{t}$ ? It is straightforward to calculate that

$$
\left.\frac{d W_{t}}{d V_{t}}\right|_{R_{0}}=\left.\frac{d W_{t}}{d V_{t}}\right|_{U^{*}}=-1
$$

Within this regime, a regression of bequeathable wealth on Social Security wealth (calculated with simple discounting), controlling for total rescurces, would confirm the "dollar-for-dollar" substitution hypothesis. Furthermore, the regression coefficient would measure a "pure" substitution effect, as in simple life cycle models with certain horizons.

In Case IIa, the pure substitution effect may be substantially less than dollar for dollar, due to the presence of binding constraints. Analyses of asset-annuity substitution based on simple discounting will yield only an approximation of this effect. In what follows, we show that the accuracy of this approximation is determined by $\xi$, as defined in Section 2. Thus, simple discounting is appropriate for behavioral savings equations precisely when it yields a satisfactory approximation to compensating variation!

First, we calculate the pure substitution effect by differentiating the optimal program implicitly, as in Section 2. We find:

$$
\left.\frac{d W_{t}}{d V_{t}}\right|_{U^{*}}= \begin{cases}-1+e^{(g-r)(T-L)}\{\psi(t)+(1-\psi(t))(1-\phi)\} & t<L \\ -1+e^{(g-r)(T-t)}\{\psi(t)+(1-\psi(t))(1-\phi)\} & t \geqq L\end{cases}
$$


where

$$
\psi(t)=\frac{1-e^{(\gamma-r) t}}{1-e^{(\gamma-r) T}} .
$$

For $t=0, \psi=0$, so our result is consistent with that of Section 2 . As $t$ rises, $\psi$ rises, and the rate of substitution falls smoothly to 0. This does not, however, imply that annuitization is worthless: since the policy is fully anticipated, endogenous readjustments in the wealth profile simple minimize changes in wealth near the date at which liquidity constraints bind. If $T$ is large relative to $t$, substitution will be nearly dollar-for-dollar.

Now suppose that we attempt to measure this pure substitution effect as before by estimating a regression of bequeathable wealth on Social Security wealth and total resources, where simple discounting is used to value annuity streams. We this yield an accurate approximation of pure behavioral substitution? Rather than fixing utility as above, we fix $R_{0}$ and differentiate:

$$
\left.\frac{d W_{t}}{d V_{t}}\right|_{R_{0}}=\left\{\begin{array}{ll}
-1+e^{(g-r)(T-L)} \psi(t) & t<L \\
-1+e^{(g-r)(T-t)} \psi(t) & t \geqq L
\end{array} .\right.
$$

Using the facts that $r>\gamma$ and $r>g$, it is easy to see that

$$
0 \geqq\left.\frac{d W_{t}}{d V_{t}}\right|_{U^{*}} \geqq\left.\frac{d W_{t}}{d V_{t}}\right|_{R_{0}} \geqq-1
$$


That is, the use of simple discounting overstates the rate of substitution, but the estimated rate should lie between 0 and -1 . How accurate is the approximation? By comparing (16) and (17), we see that

$$
\left.\frac{d W_{t}}{d V_{t}}\right|_{U^{*}}-\left.\frac{d W_{t}}{d V_{t}}\right|_{R_{0}}= \begin{cases}(1-\psi(t)) \xi & t<L \\ \left.(1-\psi(t)) e^{(r-g)(t-L)}\right)_{\xi} & t \geqq L\end{cases}
$$

where $\xi$ is the adjustment factor discussed in Section 2. In both cases, the multiplicative term associated with $\xi$ lies between 0 and 1. Thus, the error induced by using simple valuation is bounded by $\xi--$ the use of simple discounting in behavioral savings relations is justified whenever it yields a good approximation to compensating variation. If liquidity constraints eventually bind for most consumers, we would not expect to find evidence of dollar-for-dollar substitution. What rates of displacement are plausible, and how well will estimates based on simple discounting approximate true values? In Table 2, we present sample calculations for the cases labelled 1 and 3 in Table 1 (note that Case 3 is the least favorable to simple discounting when $r=0.03$ or 0.05$)$. We present both the pure substitution effect and our approximation for two ages--t $=20$ represents an individual (or sample of individuals) in the middle of his working life, while $t=40$ represents an individual at retirement. Values of the pure substitution effect range between $56 \phi$ and $78 \phi$ on the dollar; approximations based on simple discounting are generally quite accurate. 
Suppose instead that, as in most empirical work, we employed actuarial valuation of annuity benefit streams. How would we interpret an estimated "rate of displacement"? We will focus entirely on Case Ia (the "easy" case), since it allows us to illustrate the important principles. Paralleling our previous analysis, we will denote actuarial valuations as follows:

$$
V_{t}^{a}= \begin{cases}\frac{A_{t}}{r+\pi-g} & t \geqq L \\ e^{(\pi+r)(t-L)} V_{L}^{a} & t<L\end{cases}
$$

and

$$
R_{t}^{a}=w_{t}+V_{t}^{a}
$$

First, it is easy to see the basis for Hubbard's [1984] result, that an actuarially fair Social Security system will displace bequeathable wealth accumulation by more than the taxes paid. We can think of such a system as a combination of one which is fair in the sense of simple discounting, with one which entails benefits, but no taxes. The first portion would displace savings dollar-for-dollar. The subsidy late in life generates an income effect, which increases consumption in every period, thereby depressing savings prior to retirement even further. Note, however, that this result is quite sensitive to the assumption that we are in regime Ia. In other regimes, the first portion of the system generates less than dollar-for-dollar substitution, and the net result is ambiguous. 
Most empirical studies of these issues, however, measure the rate of displacement as $d W_{t} / d V_{t}^{a} \mid R_{t}^{a}$, rather than $d W_{t} / d T \mid R_{t}^{a}$ (where $T$, here, refers to taxes). As we will see, the choice of denominator makes an enormous difference.

We begin by calculating the pure rate of substitution between bequeathable wealth and actuarially valued annuities in regime Ia. It is easy to see that

$$
\left.\frac{\mathrm{dW}_{t}}{d V_{t}^{\mathrm{a}}}\right|_{\mathrm{U}^{*}}=-\frac{\mathrm{r}+\pi-\mathrm{g}}{\mathrm{r}-\mathrm{g}}<-1
$$

That is, income effects aside, we would expect to observe more than dollar-for-dollar substitution, because the use of actuarial valuation has changed the units of measurement. We refer to this as the "scale effect."

In addition, we will have an income effect as before. However, given our current choice of denominator, the income effect works in the opposite direction. This may seem counterintuitive, but is simply a matter of what one chooses to hold constant. By employing $\Delta V_{t}^{a}$ as the denominator, we must perform our decomposition by holding the change in benefits, rather than the change in taxes constant. That is, we decompose an actuarially fair system into a system which is fair in the sense of simple discounting (and which has the same benefits), plus a tax rebate. The first portion will displace resources at the rate indicated in Equation (18). Since the marginal propensity to consume the tax 
rebate is less than one, the second component will increase wealth accumulation, depressing the rate of displacement. The net result is ambigrous.

Formally, a regression of bequeathable wealth on Social Security wealth and total resources (employing actuarial discounting) would estimate the rate of displacement to be

$$
\left.\frac{d W_{t}}{d V_{t}^{a}}\right|_{t} R_{t}^{a}= \begin{cases}-\left[e^{\left.\pi(L-t) \frac{r+\pi-\varepsilon}{r-g}\left(1-e^{(\gamma-r) t}\right)+e^{-\pi t} e^{(\gamma-r) t}\right]}\right. & t<I \\ -\left[\frac{r+\pi-g}{r-g}\left(1-e^{(g-r) L+(\gamma-g) t}\right)+e^{-\pi L} e^{(g-r) L+(\gamma-g) t}\right] & t \geqq L\end{cases}
$$

These expressions are quite complex, but one can reach certain qualitative conclusions. The derivative can, in both cases be either greater or less than -1 (we will see examples below). For $t<L$, is always negative; however, it may be positive for $t>L$ (this is true even when taxes are used as the denominator--by moving sufficiently far into retirement, one puts the income effect into the past, reversing its impact).

This analysis suggests that the use of actuarial valuation confounds efforts to measure behavioral substitution between compulsory annuities and bequeathable assets, in part because of a scale effect, and in part because the introduction of an actuarially fair Social Security system generates a blend of income and substitution effects. The problem is sufficiently severe that theory yields essentially no prediction as to the magnitude of the relevant regression coefficient, or (if the sample includes retirees) even its sign! While such estimates may be valid for assessing the "reduced form" impact of Social 
Security on capital accumulation, (although, see below) they do not allow us to evaluate theories of behavior. Nevertheless, we may evaluate estimates based on actuarial valuation by comparing them with the predictions of our model for particular, reasonable parameter values. Sample calculations are presented in Table 3. Since our analysis of actuarial valuation has focused on regime Ia, we cannot employ the parameter values used in Tables 1 and 2 (which correspond to IIa). Instead, we take $r=\pi=0.03$, $I=40, g=0$ and -0.03 , and $r=0$ and 0.02 . Note that the rate of displacement tends to rise, then fall with age. Further, for the most reasonable case $(\gamma, g$ near zero) it substantially exceeds unity (the scale effect dominates). By increasing the gap between $\gamma$ and $g$, one can drive the rate of displacement below unity, even changing its sign in extreme cases.

These calculations shed rather a different light on existing estimates of asset-annuity substitution. Since it is commonly presumed that pure theory predicts dollar-for-dollar displacement, estimates of $50 \$$ to $75 \$$ on the dollar have been interpreted as roughly consistent with life cycle behavior. However, the coefficient actually predicted by theory (assuming reasonable parameter values) may be twice as large. This suggests that existing estimates are consistent with much more limited asset-annuity substitution than was previously believed. However, the analysis points to at least one more problem with existing estimates of displacement, even when they are interpreted as reduced forms for the aggregate effect (income and substitution) of an 
actuarially fair Social Security system on savings. Specifically, for the age group which dominates most microeconomic cross-sections (40 to 60 , and over), the rate of displacement falls with age. Thus, specifications should include an interaction term between age and Social Security wealth. A moment's reflection suggests that, implicitly, common specifications do include such an interaction. To step outside our formal model, survival probabilities decline with age, which makes actuarial values fall, or equivalently, makes the "scale effect" rise. Thus, these specifications constrain the rate of displacement to rise with age, exactly contrary to the predicted pattern. The effect of this mispecification may be to weaken the link between measured Social Security wealth and behaviorally relevant variables, and might account for the magnitude of existing estimates.

It is worth noting that Diamond and Hausman [1980] did not employ actuarial valuation in their study, but instead simply included the yearly benefit as an explanatory variable. Within the context of our model, it is natural to think of the estimated coefficient as measuring $1 /(r-g)$ times the pure rate of subsitution. Yet for reasonable values of $r$ and $g$, their estimates suggest a rate of displacement far below any of those calculated earlier for reasonable parameter values. This is consistent with our evaluation of the evidence based on actuarial discounting. It is not clear, however, that their procedure controls for lifetime resources in a way which includes the insurance value of annuities. Since their estimated coefficient therefore subsumes an income effect, it may significantly understate the true rate of substitution. 


\section{B. Age-Wealth Profiles}

Until recently, most evidence on age-wealth profiles among the elderly has suggested that consumers do not significantly deplete accumulated resources after retirement, contrary to the predictions of simple life cycle models (see, for example, Lydall [1955], Projector and Weiss [1966], Projector [1968], and Mirer [1982]). Studies by Diamond and Hausman [1980], King and Dicks-Mireaux [1982] and Bernheim [1984a] have criticized the empirical methodology underlying these earlier estimates, and have found to the contrary that bequeathable wealth declines significantly after retirement.

Yet there is an additional problem with using this evidence to test life cycle predictions: a very large fraction of the total resources available to many retired individuals is locked into nonbequeathable annuities. It has frequently been argued that the inclusion of annuities would vindicate the hump-shaped age-wealth profile, since the actuarial value of survival contingent claims falls with age (single year survival probabilities decline). Thus, Mirer [1979] concedes that, "to some extent, perhaps a great one for many people, pension and Social Secruity programs tend to institutionalize the tenets of the life cycle theory." Likewise, King and Dicks-Mireaux [1983] find evidence of "a clear life-cycle pattern" when the actuarial value of annuity claims are included in measures of net worth.

Yet if one wishes to infer an age-wealth profile in order to judge the plausibility of life cycle motives, the analysis of Section 2 suggests that actuarial valuation is inappropriate. Instead, we would expect simple discounting to better approximate the relevant notion of 
value. Since this measure changes very little with age, proper computation of age-wealth profiles will reverse the conclusion of King and Dicks-Mireaux: the inclusion of annuities will reinforce earlier findings that resources decline only slightly, if at all, after retirement. In Bernheim [1984a], we employ simple discounting of annuity benefits in calculations of age-wealth profiles, and find little evidence of rapid resource depletion even though bequeathable assets appear to decline rapidly after retirement. It may, of course, be inappropriate to use the compensating variation as a measure of annuity valuation when calculating wealth trajectories. For ths reason, we also examine the accuracy of the approximation entailed by the use of simple discounting. In particular, we show that, for $\gamma<g$, the behavioral rate of depletion $(\gamma)$ is bounded between the depletion rate for bequeathable resources, $\gamma$, and the depletion rate for total resources, $\gamma^{r}$, where total resources are defined to include the simple discounted value of annuity benefits:

$$
\gamma^{W}<\gamma<\gamma^{r}
$$

For a range of hypothetical parameter values, the upper bound $\left(\gamma^{r}\right)$ is in fact a much better approximation of $\gamma$. When $\gamma>g$, it is easy to see (equation $(7)$ ) that simple discounting is exactly appropriate $\left(\gamma^{r}=\gamma\right)$.

\section{Retirement}

In recent years, a large number of authors have examined the effect of Social Security on work incentives (see, for example, Boskin and Hurd [1978], Blinder, Gordon, and Weiss [1980], Burkhauser [1980], 
Hurd and Boskin [1981], and Burtless and Moffitt [1983]). Kotlikoff and Wise [1984] have also corsidered the relationship between the structure of private pension plans and labor force incentives. In most studies of pensions and retirement, the effect of continued labor force participation on the actuarial value of pension benefits plays a prominent role. Yet in a life cycle world, any inducement to retirement built into pension plans cannot arise from mortality rates. Calculations based on actuarial values will therefore tend to overstate the incentive effects of pensions. $13 /$

We must qualify this conclusion in two ways. First, estimation of pension induced work disincentives is not intrinsically tied to pure life cycle assumptions (unlike the prediction of dollar-for-dollar asset-annuity substitution, or the computation of meaningful age-wealth profiles). Under the maintained hypotheses that individuals have bequest motives and annuity markets are perfect, the use of actuarial values is sensible. Second, we have not explicitly shown that simple discounting is, under life cycle assumptions, approximately appropriate within this particular behavioral context. Unfortunately, our model is not sufficiently rich to permit consideration of endogenous retirement. Yet the fundamental insights still seem applicable: if non-negativity constraints on bequeathable wealth will never bind, simple discounting yields the proper behavioral variable; if these constraints bind only in the distant future, than this measure will be approximately appropriate. 


\section{Distribution}

The public provision of Social Security has important distributional implications. In considering these issues, Hurd and Shoven [1983], Kotlikoff [1983], Pellechio [1983], and others have typically employed actuarial valuation of annuity benefits. While the analysis of distribution is not intrinsically tied to life cycle assumptions, it is noteworthy that the use of simple discounting (associated with the assumption of pure life cycle motives) would dramatically alter many of the conclusions which appear in this literature.

In particular, many results based on actuarial valuation are driven by the observation that annuity wealth rises with survival probabilities. Thus, while consumers make the same contributions to Social Security irrespective of race and sex, whites receive in return more than blacks; women more than men. Yet if one assumes life cycle behavior with missing annuity markets and uses compensating variation to measure value, equal yearly benefits generate equal return. From this point of view, the current Social Security system seems entirely equitable.

Once again, simple discounting is, of course, not exactly appropriate even in a pure life cycle world. Furthermore, individuals with high survival probabilities will tend to have large T's, so that there will be some vestigial correlation between survival probabilities and value. However, the calculations of Section 2 appear to suggest that actuarial valuation will significantly overstate these differences. 
E. Wage Taxes vs. Consumption Taxes

"Textbook" wisdom holds that proportional wage taxes and consumption taxes are equivalent, from the point of view both of the individual, and of the government. In recent years, this belief has been modified by the recognition that there are important transitional distinctions between these two taxes (see, for example, Auerbach, Kotlikoff, and Skinner [1981]). The current analysis raises a second potentially important set of distinctions, which arise when lifetimes are uncertin. If annuity markets are perfect, then, as in the textbook case, a wage tax and a consumption tax which raise the same expected revenue will be equivalent from the individual's point of view. When annuity markets are either imperfect or fail completely, this equivalence dissolves.

Consider a pure life cycle saver who has no access to private annuity markets, and suppose his lifetime consumption plan places him in regime Ia (for simplicity, no constraints bind). He will be indifferent between proportional wage and consumption taxes as long as the simple discounted value (ignoring death) of tax payments is the same for each. However, since the government taxes many individuals, it is concerned with expected revenue. Since wage taxes raise revenue sooner, the wage tax raises more expected revenue. Equivalently, if the government wishes to raise a certain amount of revenue, consumers would prefer to have the tax applied to wages, rather than to consumption. The potential importance of this observation is clear when one considers the nature of transitional distinctions between wage and consumption taxation--the wage tax raises less revenue in the short mu, because the 
consumption tax falls heavily on retirees. Considerations based on uncertin lifetimes work in the opposite direction, offsetting this effect.

Of course, this result is driven by the assumption that market imperfections make it more efficient for government, rather than individuals, to save. This property holds for some, but not all, models of adverse selection (see King [1984], and Eckstein, Eichenbaum, and Peled [1983]).

\section{Concluding Remarks}

When annuity markets are perfect and individuals have bequest motives, actuarial valuation of benefits is clearly appropriate. In this paper, we have shown that, when annuity markets are missing and individuals have no bequest motives, simple discounting of benefits yields a good approximation to the appropriate concept of value. Between these two polar, "easy" cases, there is a range of possibilities for which the valuation of annuities is significantly more difficult. Calculation of realistic annuity values must recognize not only the existence of potentially significant bequest motives, but also the potential imperfections in annuity markets, including idiosynchratic intrafamily arrangements designed to improve upon imperfect markets (see, for example, Kotlikoff and Spivak [1981], and Bernheim, Shleifer and Summers [1984]). These important intermediate cases are left for future work. 
Figure 1

Case Ia: $\gamma>\mathrm{g}, \mathrm{W}_{\mathrm{L}}>0$
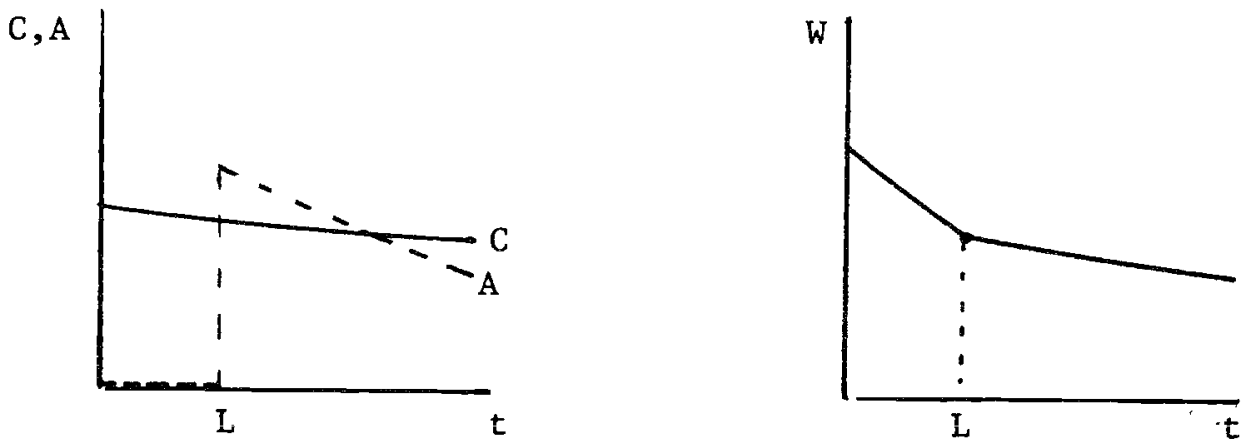

Case Ib $: \gamma>\mathrm{g}, \mathrm{W}_{\mathrm{L}}=0$
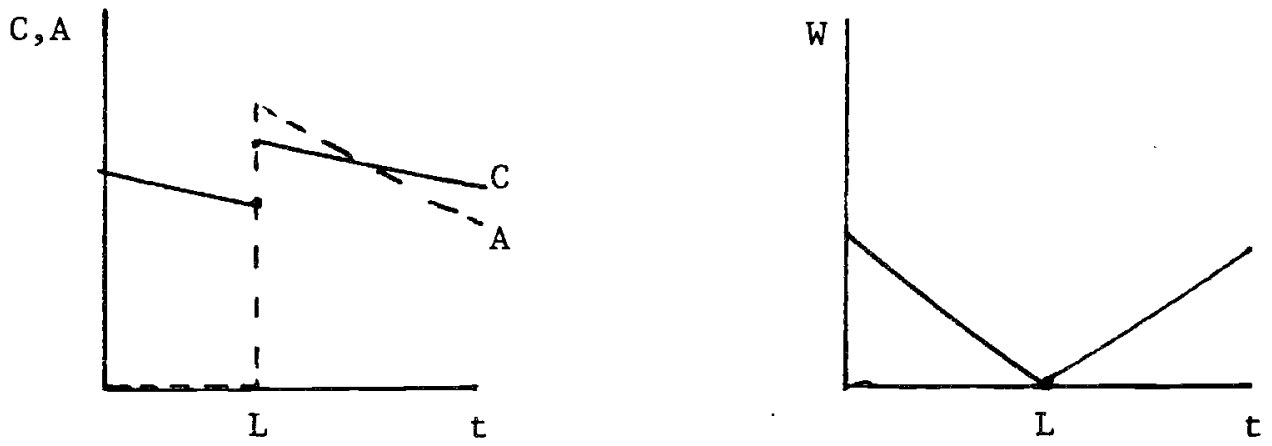

Case IIa: $\gamma<\mathrm{g}, \mathrm{W}_{\mathrm{L}}>0$
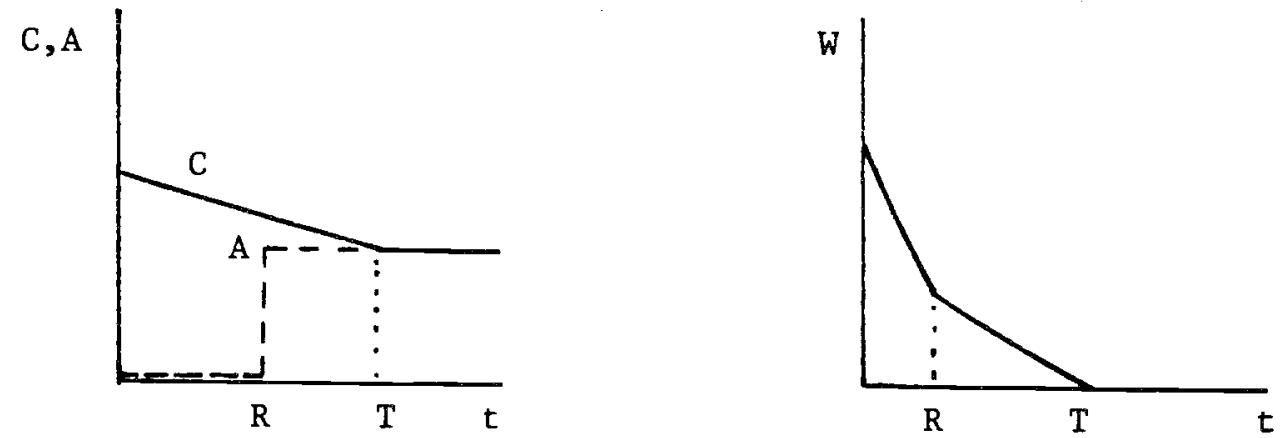

Case IIb: $\quad \gamma<\mathrm{g}, \mathrm{W}_{\mathrm{L}}=0$
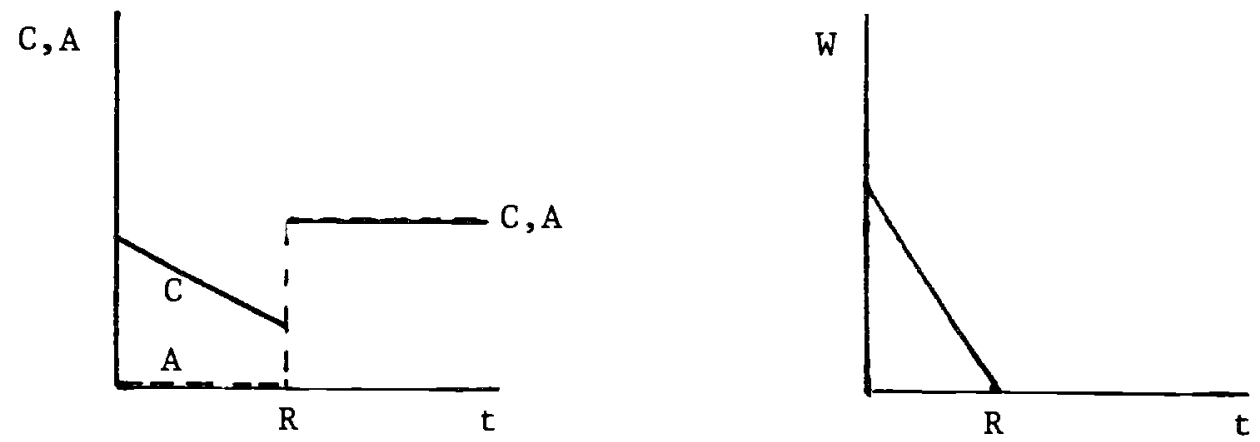
$\underline{\text { Table } 1}$

Annuity Valuation for Hypothetical Parameter Values

\begin{tabular}{|c|c|c|c|c|c|c|c|}
\hline \multirow[t]{2}{*}{ Case \# } & \multicolumn{3}{|c|}{ Exogenous Parameters } & \multicolumn{4}{|c|}{ Calculated Values } \\
\hline & $\mathrm{r}$ & $\lambda$ & $\alpha$ & $\gamma$ & $\mathrm{T}$ & $\frac{\mathrm{MV}}{\mathrm{SDV}}$ & $\frac{\mathrm{AV}}{\mathrm{SDV}} *$ \\
\hline 1 & .03 & .05 & 0 & -.020 & 41.9 & 0.886 & 0.936 \\
\hline 2 & .03 & .05 & -1 & -.010 & 67.1 & 0.947 & 0.978 \\
\hline 3 & .03 & .05 & -2 & -.007 & 89.7 & 0.973 & 0.990 \\
\hline 4 & .03 & .07 & 0 & -.040 & 26.6 & 0.743 & 0.822 \\
\hline 5 & .03 & .07 & -1 & -.020 & 41.9 & 0.837 & 0.908 \\
\hline 6 & .03 & .07 & -2 & -.013 & 54.9 & 0.890 & 0.947 \\
\hline 7 & .05 & .05 & 0 & 0.0 & $\infty$ & 1.000 & 1.000 \\
\hline 8 & .05 & .05 & -1 & 0.0 & $\infty$ & 1.000 & 1.000 \\
\hline 9 & .05 & .05 & -2 & 0.0 & $\infty$ & 1.000 & 1.000 \\
\hline 10 & .05 & .07 & 0 & -.020 & 35.4 & 0.951 & 0.978 \\
\hline 11 & .05 & .07 & -1 & -.010 & 58.2 & 0.984 & 0.995 \\
\hline 12 & .05 & .07 & -2 & -.007 & 79.4 & 0.995 & 0.995 \\
\hline 13 & .01 & .05 & 0 & -.040 & 39.2 & 0.459 & 0.547 \\
\hline 14 & .01 & .05 & -1 & -.020 & 61.5 & 0.567 & 0.674 \\
\hline 15 & .01 & .05 & -2 & -.013 & 79.9 & 0.640 & 0.751 \\
\hline 16 & .01 & .07 & 0 & -.060 & 30.0 & 0.365 & 0.448 \\
\hline 17 & .01 & .07 & -1 & -.030 & 47.3 & 0.469 & 0.570 \\
\hline 18 & .01 & .07 & -2 & -.020 & 61.5 & 0.536 & 0.650 \\
\hline
\end{tabular}

*These calculations are based on trapazoidal approximations of the appropriate integrals. Since the marginal valuation function is monotonic, it is possible to obtain bounds on the true integral by employing rectangular approximations. Such calculations suggest that every entry in this column is within 0.01 of its true value (most bounds are, in fact, much tighter). 


\section{Footnotes}

1) Bernheim, Shleifer and Summers [1984] have considered the problem of enforceability in a non-cooperative context.

2/ Kotlikoff and Spivak's calculations ignore the fact that the deaths of elderly spouses tend to be highly correlated.

3/ Note that we assume single year conditional survival probabilities are constant over time. In such a world, the actuarial value of an annuity with constant benefits does not change with age. In what follows, it should be clear that our central results do not depend upon this assumption. In particular, the argument which establishes that simple discounting is approximately appropriate depends only upon there being a relatively long interval before the nonnegativity constraint on bequeathable wealth binds. To take an extreme alternative, suppose death will occur at date $T$, with certainty. If an annuity contract promises to pay benefits past this date, those benefits are irrelevant. The appropriate value of an annuity (assuming either that the individual can borrow on benefits paid prior to $\mathrm{T}$ or that terminal benefits are not too large) is then just the simple discounted value of benefits, up to age $T$. In this very special case, actuarial valuation is exactly appropriate, and our technique (which includes benefits promised after $T$ ) is clearly in error. However, we have added the qualification that there must be a relatively long interval before the constraint on bequeathable wealth binds. Here, it binds as $\mathrm{T}$, so if $\mathrm{T}$ is large, our method is, again, approximately appropriate. In general, however, if there is some maximum age, one could always improve our measure by excluding benefits promised after the maximum age.

4/ One may think of this both as an inherited endowment and as human capital. In fact, nothing of substance would change if a preretirement income stream were substituted for $\mathrm{w}_{0}$, to incorporate earned income explicitly.

5/ Partially or completely relaxing this constraint only strenthens our conclusion that simple discounting is appropriate.

6) The transversality condition guarantees this inequality.

I/ For example, if $r>\lambda$ and $g \leqq 0, \gamma \geqq g$, and whether (4) binds is independent of $a$.

8/ Throughout, details of all calculations are ommitted, but are available from the author upon request. 


\section{$-37-$}

9/ This result can be understood as follows. Since $\lambda>r$, the individual wishes to consume all resources immediately. He cannot borrow on annuities, so annuitization forces him to defer consumption to the future. Thus, annuitization generates at net loss given actuarially fair financing.

10/ This formula matches our previous result (Equation (14)) in the borderline case where $\mathrm{T}=\mathrm{L}$ and $\mathrm{C}_{\mathrm{L}-}=\mathrm{C}_{\mathrm{L}+}$.

11/ See, for example, Feldstein and Pellechio [1979], Kotlikoff [1979] and King and Dicks-Mireaux [1982]. A notable exception is Diamond and Hausman [1980].

12/ The inconsistency would disappear if each individual belonged to a sufficiently large risk-pooling family, as discussed in the introduction.

13/ I would like to thank Michael Hurd for pointing this effect out to me. 


\section{References}

Auerbach, A., L. Kotlikoff and J. Skinner [1981], "The Efficiency Gains from Dynamic Tax Reform," Harvard Institute for Economic Research Discussion Paper No. 870.

Bernheim, B.D. [1984a], "Dissaving After Retirement: Testing the Pure Life Cycle Hypothesis," in Z. Bodie, J. Shoven, and D. Wise (eds.), Pensions and Retirement in the United States, NBER Conference volume, forthcoming.

Bernheim, B.D. [1984b], "Annuities, Pensions, and Private Wealth," mimeo, Stanford.

Bernheim, B.D., A. Shleifer and L. Summers [1984], "Bequests as a Means of Payment," NBER Working Paper No. 1303.

Blinder, A., R. Gordon and D. Wise [1980], "Social Security, Bequests, and the Life Cycle Theory of Saving: Cross-Sectional Tests," NBER Working Paper No. 619.

Boskin, M. and M. Hurd [1978], "The Effects of Social Security on Early Retirement," Journal of Public Economics vol. 10.

Burkhauser, R. [1980], "The Early Acceptance of Social Security: An Asset Maximization Approach," Industrial and Labor Relations Review, Vol. 33 .

Burtless, G. and R. Moffitt [1983], "The Effect of Social Security on Labor Supply of the Aged: The Joint Choice of Retirement Date and Post-retirement Hours of Work," (mimeo).

Diamond, P. and J. Hausman [1980], "Individual Savings Behavior," MIT (mimeo).

Eckstein, Z., M. Eichenbaum and D. Peled [1983], "Uncertain Lifetimes and the Welfare Enchancing Properties of Annuity Markets and Social Security," mimeo, GSIA, Carnegie-Mellon.

Feldstein, M. [1974], "Social Security, Induced Retirement, and Aggregate Capital Accumulation," JPE, vol. 82, pp. 905-926.

Feldstein, M. and A. Pellechio [1979], "Social Security and Household Wealth Accumulation: New Microeconomic Evidence," Review of Economics and Statistics, vol. 61 .

Hubbard, R. Glenn [1984], "Undertain Lifetimes, Pensions, and Individual Savings," NBER Working Paper No. 1363. 
Hurd, M. and M. Boskin [1981], "The Effect of Social Security on Retirement in the Early 1970's," NBER Working Paper No. 659.

Hurd, M. and J. Shoven [1983], "The Distributional Impact of Social Security," Stanford (mimeo).

King, M. [1984], "Tax Policy and the Business Cycle," mimeo, MIT.

King, M. and Dicks-Mireaux, L. [1982], "Asset Holding and the Life Cycle," Economic Journal, vol. 92, pp. 247-67.

King, M. and Dicks-Mireaux, L. [1983], "Pension Wealth and Household Savings: Tests of Robustness," Journal of Public Economics, forthcoming.

Kotlikoff, L. [1979], "Testing the Theory of Social Security and Life Cycle Accumulation," The American Economic Review, vol. 69, pp. 396410 .

Kotlikoff, L. [1983], "The Distributional Impact of Social Security," presented at the CEPR Conference on Social Security at Stanford University.

Kotlikoff, L. and A. Spivak [1981], "The Family as an Incomplete Annuities Market," JPE, vol. 89, pp. 372-9l.

Kotlikoff, L. and D. Wise [1984], "The Structure of Private Pension Plans and Labor Force Incentives," in Z. Bodie, J. Shoven, and M. Hurd (eds.), Pensions and Retirement in the United States, NBER Conference volume, forthcoming.

Lydall, H. [1955], "The Life Cycle in Income, Saving and Asset Ownership," Econometrica vol. 46, pp. 985-1012.

Mirer, T. [1979], "The Wealth-Age Relationship Among the Aged," American Economic Review, vol. 69, pp. 435-43.

Pellechio, A. [1983], "Individual Gains and Losses from Social Security and an Agenda for Reform," mimeo.

Projector, D. [1968], Survey of Changes in Family Finances, Federal Reserve Board of Governors.

Projector, D. and G. Weiss [1966], Survey of Financial Characteristics of Consumers, Federal Reserve Board of Governors.

Yaari, M. [1965], "Uncertain Lifetime, Life Insurance, and The Theory of the Consumer," Review of Economic Studies, vol. 32, pp. 137-50. 